patients without cataract $(p=0,034)$. Analysis of $G C$ treatment effect on co-morbidities revealed a significant increase in prevalence of diabetes (after 3 months) and cataract (after 5 years) compared to baseline. BMI was significantly higher after one year and five years of GC treatment. PMR patients with cataract at baseline required longer treatment with $\mathrm{GCs}(\mathrm{p}=0.023)$. Presence of other metabolic features at the time of GCA or PMR diagnosis did not affect the treatment duration (Figure 1). Conclusion: Newly-diagnosed GCA and PMR patients did not appear to have a healthier metabolic profile than HCs. As expected, GC treatment resulted in the development of an unhealthier metabolic profile in GCA patients. In PMR patients, the presence of cataract at baseline was predictive for a prolonged treatment period which could be explained by higher ESR levels in PMR patients with cataract. Together, our findings emphasize the importance of novel GC sparing therapeutic agents and personalized medicine in GCA and PMR.

REFERENCES:

[1] Buttgereit F,et al. Prevention of glucocorticoid morbidity in giant cell arteritis. Rheumatol (United Kingdom). 2018.

[2]Ungprasert $P$, et al. Lower body mass index is associated with a higher risk of giant cell arteritis: A systematic review and meta-analysis. Ann Transl Med. 2015.

Disclosure of Interests: Idil Esen: None declared, Philip Therkildsen: None declared, Berit Dalsgaard Nlelsen: None declared, Anna van 't Ende: None declared, Annemieke Boots Consultant of: Grunenthal, Peter Heeringa: None declared, Ellen-Margrethe Hauge: None declared, Elisabeth Brouwer Speakers bureau: Roche, fees paid to UMCG, Yannick van Sleen: None declared DOI: 10.1136/annrheumdis-2021-eular.2425

\section{OP0068 AND TOCILIZUMAB IN TAKAYASU ARTERITIS: MULTICENTER WORLDWIDE RETROSPECTIVE STUDY OF 209 PATIENTS}

A. Mekinian ${ }^{1}$, L. Biard ${ }^{2}$, L. Dagna ${ }^{3}$, P. Jégo ${ }^{4}$, C. Salvarani ${ }^{5}$, M. Sergey ${ }^{6}$, O. Espitia ${ }^{1}$, S. Sciascia ${ }^{7}$, P. Hernan ${ }^{8}$, P. Cacoub ${ }^{1}$, O. Fain ${ }^{1}$, D. Saadoun ${ }^{9}$ on behalf of TAK FRENCH GROUP. ${ }^{1}$ Saint Antoine, Internal Medicine, Paris, France; ${ }^{2}$ Saint Antoine, SDF, Paris, France; ${ }^{3}$ Saint Antoine, QF, Paris, Italy; ${ }^{4}$ Saint Antoine, SFD, Paris, France; ${ }^{5}$ Saint Antoine, Internal Medicine, Itale, Italy; ${ }^{6}$ Saint Antoine, Internal Medicine, Moscou, Russian Federation; ${ }^{7}$ Saint Antoine, Internal Medicine, Paris, Italy; ${ }^{8}$ Saint Antoine, Internal Medicine, Paris, Spain; ${ }^{9}$ Pitie, Internal Medicine, Paris, France

Background: In this large worldwide TAK registry, we report 209 patients treated with TNF- $\alpha$ antagonists and tocilizumab aiming to compare their safety and efficacy, and determine the predictive factors of treatment response and relapse. Objectives: To assess safety and efficacy of TNF- $\alpha$ antagonists and tocilizumab in patients with Takayasu arteritis (TAK).

Methods: We conducted a retrospective multicenter study in referral centers from France, Italy, Spain, Israel, Japan, Tunisia and Russia about biological-targeted therapies in TAK during the period from January 2017 to September 2019 for the data collection.

Results: Two-hundred nine patients with TAK [median age of 29 years [7-62], and $186(89 \%)$ females] were included. They received either TNF- $\alpha$ antagonists $[n=132$ (63\%) with 172 lines; infliximab $(n=109)$, adalimumab $(n=45)$, golimumab $(n=8)$, certolizumab $(n=6)$ and etanercept $(n=5)]$, or tocilizumab $[n=77(37 \%)$ with 121 lines; intravenous and subcutaneous in 95 and 26 cases, respectively]. A complete response at 6 months was evidenced in 101/152 (66\%) on TNF- $\alpha$ antagonists and $75 / 107(70 \%)$ on tocilizumab, respectively. Age $\geq 30$ years [OR= 2.09 [1.09; 3.99]] was associated with complete response, whereas vascular signs [0.26 [0.1;0.65]], baseline prednisone $\geq 20 \mathrm{mg} /$ day [0.51 [0.28;0.93]] were negatively associated with the complete response to TNF- $\alpha$ antagonists or tocilizumab. During a median follow-up of 36 months, 103 relapses were noted. Supra-aortic branches and thoracic aorta involvements [HR $2.44(1.06 ; 5.65)$ and $3.66(1.18 ; 11.4)$, respectively], and systemic signs at baseline [HR $2.01(1.30 ; 3.11)]$ were significantly associated with relapse. The cumulative incidence of treatment discontinuation and relapse were similar in TNF $\alpha$ antagonists and tocilizumab. Fifty-eight (20\%) adverse effects occurred on biological-targeted therapies of whom $37(21 \%)$ and $21(17 \%),(p=0.4)$ on TNF- $\alpha$ antagonists and tocilizumab, respectively

Conclusion: This large multicenter study shows high efficacy of biological-targeted treatments in refractory TAK. Efficacy, relapse and drug retention rate were equivalent with TNF- $\alpha$ antagonists and tocilizumab.

Disclosure of Interests: None declared

DOI: 10.1136/annrheumdis-2021-eular.2843

\section{OP0069 THE ROLE OF POSITRON EMISSION TOMOGRAPHYI COMPUTED TOMOGRAPHY (PET/CT) IN DISEASE ACTIVITY ASSESSMENT IN PATIENTS WITH LARGE VESSEL VASCULITIS}

E. Galli ${ }^{1}$, F. Muratore ${ }^{2}$, L. Boiardi ${ }^{2}$, M. I. Casali ${ }^{3}$, A. Versari ${ }^{3}$, G. Besutti ${ }^{4}$, L. Spaggiari ${ }^{4}$, P. Mancuso ${ }^{5}$, P. Giorgi Rossi ${ }^{5}$, C. Salvarani ${ }^{1,2} .{ }^{1}$ University of
Modena and Reggio Emilia, Department of Rheumatology, Modena, Italy; ${ }^{2}$ Rheumatology Unit, Azienda USL-IRCCS di Reggio Emilia, Department of Specialistic Medicine, Reggio Emilia, Italy; ${ }^{3}$ Nuclear Medicine Unit, Azienda USL-IRCCS di Reggio Emilia, Department of Oncology and Advanced Technology, Reggio Emilia, Italy; ${ }^{4}$ Radiology Unit, Azienda USL-IRCCS di Reggio Emilia, Department of Imaging and Laboratory Medicine, Reggio Emilia, Italy; ${ }^{5}$ Epidemiology Unit, Azienda Unità Sanitaria Locale-IRCCS di Reggio Emilia, Department of Epidemiology Service, Reggio Emilia, Italy

Background: Assessment of disease activity in large vessel vasculitis (LVV) is still an unmet need. PET Vascular Activity Score (PETVAS) is a new composite score aimed at quantifying the overall inflammatory burden by adding together PET qualitative visual scores (0-3, according to Meller) in nine selected arteria regions (1). In two independent cohorts, PETVAS showed to be effective in discriminating between patients with clinically active and inactive vasculitis.

Objectives: To assess the role of PET/CT and the performance of PETVAS in differentiating between clinically active and inactive vasculitis in a single center cohort of patients with LVV.

Methods: One-hundred patients with radiographic evidence of LVV were enrolled by the Rheumatology Unit of Reggio Emilia Hospital (Italy) between June 2007 and September 2020. All subjects underwent full clinical, laboratory and imaging evaluation (including PET/CT) at baseline, annually and when a relapse was suspected. Medical records of recruited patients were retrospectively reviewed from baseline visit until 30 September 2020, last follow-up or death.

For each PET/CT test, the nuclear medicine physician's interpretation of scans (active/inactive vasculitis) was compared with disease activity clinical judgement (active disease/remission). The latter was based on comprehensive signs/symptoms assessment, laboratory and imaging (excluding PET/CT) data and was considered the reference standard.

For each PET/CT scan, PETVAS score was calculated and its performance in discriminating between patients with active and inactive disease was compared to clinical judgement.

Results: In the study period 100 LVV patients [51 giant cell arteritis (GCA), 49 Takayasu arteritis (TAK)] underwent a total of 474 PET scans. Nuclear medicine physician's interpretation of PET/CT was able to discriminate between patients in clinically active LVV ( $n$ 167) and those in clinical remission ( $n$ 307) with a sensitivity of $60 \%$ ( $95 \% \mathrm{Cl}, 51$ to $69 \%$ ) and a specificity of $80 \%(95 \% \mathrm{Cl}, 75$ to $84 \%$ ). The following sensitivity and specificity values were found in LVV subgroups: $73 \%(95 \% \mathrm{Cl}, 59$ to $84 \%)$ and $77 \%(95 \% \mathrm{Cl}, 70$ to $83 \%)$ for TAK, and $51 \%(95 \%$ $\mathrm{Cl}, 38$ to $63 \%)$ and $82 \%(95 \% \mathrm{Cl}, 76$ to $88 \%)$ for $\mathrm{GCA}$, respectively.

LVV patients with higher PETVAS scores were more frequently classified as having active disease: age and sex adjusted OR $1.15(95 \% \mathrm{Cl}, 1.11$ to 1.19$)$ $\mathrm{p}<0.0001$. Similar results were found in LVV subgroups, [age and sex adjusted OR $1.12(95 \% \mathrm{Cl}, 1.08$ to 1.17$)$ for GCA and 1.22 (95\% Cl, 1.14 to 1.31$)$ for TAK all $\mathrm{p}<0.0001]$.

The area under receiver operating characteristics (ROC) curve (AUC) of PETVAS in differentiating between clinically active and inactive LVV was $0.73(95 \%$ $\mathrm{Cl}, 0.68$ to 0.79$)$. Similar results were found in LVV subgroups, $[0.70(95 \% \mathrm{Cl}$, 0.62 to 0.78$)$ for GCA, and $0.79(95 \% \mathrm{Cl}, 0.71$ to 0.87$)$ for TAK]. A PETVAS $\geq 10$ provided $61 \%$ sensitivity and $80 \%$ specificity in differentiating between clinically active and inactive LVV $(52 \%$ sensitivity and $82 \%$ specificity in GCA subgroup and $73 \%$ sensitivity and $78 \%$ specificity in TAK subgroup).

Conclusion: In our cohort PET/CT has shown to be useful in monitoring LVV disease activity.

PETVAS seems to be a reliable tool in helping clinicians to discriminate between LVV patients with active disease and those in remission.

REFERENCES:

[1] Grayson PC, Alehashemi S, Bagheri AA, Civelek AC, Cupps TR, Kaplan MJ, Malayeri AA, Merkel PA, Novakovich E, Bluemke DA, Ahlman MA. 18 F-Fluorodeoxyglucose-Positron Emission Tomography as an Imaging Biomarker in a Prospective, Longitudinal Cohort of Patients with Large Vessel Vasculitis. Arthritis Rheumatol. 2018 Mar;70(3):439-449. doi: 10.1002/art.40379. Epub 2018 Feb 6. PMID: 29145713; PMCID: PMC5882488.

Disclosure of Interests: None declared

DOI: 10.1136/annrheumdis-2021-eular.3713

\section{OP0070 ONSET TO DIAGNOSIS TIME PREDICTS SURVIVAL RATE IN TAKAYASU ARTERITIS}

A. Popov ${ }^{1}$, I. Borodina ${ }^{2}$, L. Shardina ${ }^{3} .{ }^{1}$ Ural State Medical University, Hospital Therapy and Urgent Medical Care Service, Ekaterinburg, Russian Federation; ${ }^{2}$ Sverdlovsk Regional Clinical Hospital 1, Therapy, Yekaterinburg, Russian Federation; ${ }^{3}$ Ural State Medical University, Higher Medical Nurse and Social Education, Yekaterinburg, Russian Federation

Background: Takayasu arteritis (TA) is large vessel vasculitis. In spite of relatively high 5 to 15 years survival rate, TA affects young persons and causes major cardiovascular events, disability and preterm deaths [1]. Nowadays, though new 